\title{
Bag Cell Extract Inhibits Tail-Siphon Withdrawal Reflex, Suppresses Long-Term but Not Short-Term Sensitization, and Attenuates Sensory-to-Motor Neuron Synapses in Aplysia
}

\author{
Jason R. Goldsmith and John H. Byrne \\ Department of Neurobiology and Anatomy, University of Texas Medical School, Houston, Texas 77225
}

The peptides released from the bag cells (bag cell peptides, $\mathrm{BCPs}$ ) in Aplysia californica are responsible for eliciting or modulating a repertoire of behaviors preceding and accompanying egg laying. Our interest was in determining to what extent behaviors that can occur simultaneously with egg laying are modulated. To address this issue, we examined the effects of an extract (bag cell extract, BCE) that contained BCPs, as well as egg-laying hormone (ELH), an identified $B C P$, on both the tail-siphon withdrawal reflex and the ability of that reflex to exhibit sensitization, a simple form of nonassociative learning. In addition, we examined the ability of BCE, as well as the individual BCPs, to modulate a component of the circuitry of the reflex. Behavioral experiments indicated that BCE inhibited the baseline withdrawal reflex and suppressed long-term sensitization of the reflex while leaving short-term sensitization unaffected. These effects were not observed in animals receiving an extract of a control ganglion or in animals receiving ELH, and therefore may be attributed to the actions of one or more BCPs, but presumably not to ELH alone. Electrophysiological experiments revealed that BCE also attenuated the monosynaptic EPSP elicited in tail motor neurons by tail sensory neurons. In subsequent experiments in which the BCPs were individually applied, only one BCP, $\beta$-BCP, significantly attenuated the EPSPs. This effect was independent of narrowing of the presynaptic action potential. Taken together, these results suggest a novel behavioral modification attributed to BCPs, inhibition of the tail-siphon withdrawal reflex, and suggest a possible locus of action and peptide candidate for this effect. In addition, these experiments raise the possibility that BCPs may exert a long-lasting effect (>24 hr), selectively blocking a simple form of long-term memory.

IKey words: Aplysia, bag cell peptides, learning and memory, long-term memory, mobilization, motor neuron, sensitization, sensory neuron, short-term memory, synaptic transmission]

Received Mar. 9, 1992; revised Sept. 8, 1992; accepted Oct. 27, 1992.

We thank Drs. D. V. Buonomano and J. P. Pieroni for their helpful comments on an earlier draft of the manuscript. We also thank M. Kabiri, E. McClendon and A. Queng for their assistance with the behavioral observations and Dr. Dennis Johnston for his assistance with the statistical analyses. This work was supported by NIH Grant T32 HD07324 to J.R.G., and NIH Grant RO1 NS 19895 and NIMH Award K02 MH 00649 to J.H.B.

Correspondence should be addressed to Jason R. Goldsmith, Department of Neurobiology and Anatomy, University of Texas Medical School, P.O. Box 20708, Houston, TX 77225.

Copyright (c) 1993 Society for Neuroscience $0270-6474 / 93 / 131688-13 \$ 05.00 / 0$
Although considerable progress has been made in understanding the actions of reproductive hormones on reproductive behavior and organs, little is known about the mechanisms by which these and other hormones affect other behaviors. For example, in addition to its classical action on the pituitary gland, luteinizing hormone-releasing hormone has effects not only on reproductive behavior but also on various forms of learning (Mora and Diaz-Veliz, 1985; Nasello et al., 1990; Mora et al., 1991). Due to the difficulty in performing cellular studies on the vertebrate CNS, however, the mechanisms by which this peptide acts remain unknown. An alternative approach is to examine these issues in the relatively simple nervous system of higher invertebrates.

The marine mollusk Aplysia may prove to be a particularly advantageous animal for the study of the modulatory effects of reproductive peptides on behavior and learning, given its simple nervous system, behaviors, and forms of learning. Indeed, several behaviors of this animal, as well as the neural circuits that mediate them, have been well characterized (Kandel, 1976, 1979). One such behavior is the tail-siphon withdrawal reflex, which consists of a coordinated set of defensive responses to stimulation of the tail, including withdrawal of the tail and siphon. The tail sensory neurons that mediate this reflex are located in the pleural ganglion. These neurons make monosynaptic excitatory connections with tail motor neurons, located in the pedal ganglion, resulting in activation of the motor neurons and withdrawal of the tail (Walters et al., 1983a). In addition, these same sensory neurons also synapse onto various interneurons in the pleural ganglion (Cleary and Byrne, 1985; $\mathrm{Xu}$ et al., 1991; Buonomano et al., 1992), some of which relay input to siphon motor neurons in the abdominal ganglion to produce withdrawal of the siphon (Cleary and Byrne, 1986).

The tail-siphon withdrawal reflex has been used to analyze the neural and molecular mechanisms of a simple form of nonassociative learning, sensitization. Sensitization is the enhancement of a behavioral response to a stimulus delivered to one area of the body after delivery of a strong reinforcing stimulus to the same or another area of the animal's body. The tailsiphon withdrawal reflex exhibits both short-term (minutes) sensitization (Walters et al., 1983b; Byrne et al., 1991) and longterm (days) sensitization (Scholz and Byrne, 1987). Short-term enhancement of the reflex is associated with heterosynaptic facilitation of the monosynaptic connections between the tail sensory neurons and tail motor neurons (Walters et al., 1983b). Using in vitro analogs of long-term sensitization training and 
classical conditioning, long-term ( $24 \mathrm{hr}$ ) facilitation of these synapses has also been demonstrated (Goldsmith and Byrne, 1989; Buonomano and Byrne, 1990; Byrne et al., 1991).

A family of endogenous peptides that may modulate both the tail-siphon withdrawal reflex and sensitization of the reflex is the bag cell peptides (BCPs). The BCPs are believed to play a key role in the neural control of reproductive behavior of $A p l y$ sia. Indeed, injection of a crude extract of the nervous system containing BCPs into a mature recipient animal reliably induces egg laying (Kupfermann, 1970) and egg-laying behaviors (Arch and Smock, 1977).

The BCPs, which include $\alpha-, \beta-$, and $\gamma$-BCP and egg-laying hormone (ELH), are synthesized and released by the bag cell neurons. These neurons are found in two homogeneous clusters of approximately 400 cells each, located in paired, bag-like structures attached to the rostral surface of the abdominal ganglion. The processes of these cells spread in many directions: laterally to the opposite cluster, along and within the more rostral extent of the pleural-abdominal connective, and into the connective tissue surrounding the abdominal ganglion and bag cells (Coggeshall, 1967; Frazier et al., 1967; Haskins et al., 1981; Sossin et al., 1990). The connective tissue sheath that surrounds these two clusters is highly vascularized and constitutes the relcase site of the BCPs into the circulatory system, as evidenced by the many granule-filled processes that end in the connective tissue sheath (Coggeshall, 1967; Frazier et al., 1967; Haskins et al., 1981; Roubos et al., 1990; Sossin et al., 1990).

Electrophysiological studies have revealed that the bag cells are normally quiescent. However, they periodically enter a prolonged phase of intense and synchronous electrical activity, termed an afterdischarge, which apparently involves all the cells of both clusters (Frazier et al., 1967; Dudek and Blankenship, 1977a,b; Pinsker and Dudek, 1977; Haskins and Blankenship, 1979). In intact animals, egg laying is invariably preceded by an afterdischarge in the bag cells (Pinsker and Dudek, 1977). During the reproductive season (summer and fall), egg laying is triggered in this manner as often as once a day (Pinsker and Parsons, 1985). The BCPs released during the afterdischarge have been identified, and the effects they exert on a variety of target neurons, including neurons in the head ganglia, have been extensively studied (Branton et al., 1978a,b; for reviews, see Mayeri and Rothman, 1985; Arch and Berry, 1989; Conn and Kaczmarek, 1989; Jung and Scheller, 1991). Target neurons in the abdominal ganglion may be affected by the release of BCPs from processes of the bag cells that terminate near these neurons. Effects on more distant targets, which may include the neurons in the pleural-pedal ganglion that mediate the tail-siphon withdrawal reflex, may require sites of local release of the BCPs or the circulatory system to transport the BC.Ps from the abdominal ganglion to the vicinity of these neurons.

Recently, bag cell-like neurons, which are immunoreactive for at least two BCPs, and functional bag cell neurites have also been found in the pleural and cerebral ganglion (Jahan-Parwar and Fredman, 1976; Chiu and Strumwasser, 1984; Shyamala et al., 1986; Pulst et al., 1988; Brown et al., 1989; Painter et al., 1989; Shope et al., 1991). The proximity of these bag cell-like neurons and bag cell neurites to the neurons that mediate the tail-siphon withdrawal reflex provides a more direct means by which the BCPs could affect the reflex. Indeed, $\alpha$-BCP inhibits giant cell LPIl of the left pleural ganglion, a cell that is involved in mucous secretion and that is inhibited during a bag cell atterdischarge (Shope et al., 1991). Thus, it is conceivable that these peptides, which have actions throughout the nervous system, may modulate other behaviors as well.

We examined the effects of an extract prepared from the bag cells (BCE), as well as ELH on both the tail-siphon withdrawal reflex, and the ability of the reflex to exhibit short- and longterm sensitization. In addition, in vitro electrophysiological experiments using a known component of the circuitry underlying the reflex were performed to gain insights into the site(s) and mechanism(s) of action of the BCPs. In these experiments the effects of BCE as well as the individual BCPs $(\alpha-, \beta-$, and $\gamma$-BCP and $\mathrm{ELH}$ ) were examined. We found that $\mathrm{BCE}$ significantly inhibited the baseline withdrawal reflex and significantly suppressed long-term sensitization of the reflex while leaving shortterm sensitization unaltered. Since these effects were not observed in animals receiving an extract of the abdominal ganglion minus the bag cells or in animals receiving ELH, they may be attributed to actions of one or more of the BCPs, but presumably not to ELH alone. In addition, BCE significantly attenuated the tail sensory-to-motor neuron connection. Further, application of the individual BCPs revealed that only one $\mathrm{BCP}, \beta-\mathrm{BCP}$, significantly attenuated the EPSPs. This effect was independent of presynaptic spike narrowing.

Aspects of this work have appeared previously in abstract form (Goldsmith and Byrne, 1990, 1991).

\section{Materials and Methods}

Animals. Aplysia californica, weighing between 125 and $500 \mathrm{gm}$, were obtained from Alacrity Marine Biological (Redondo Beach, CA), Marine Specimens Unlimited (Pacific Palisades, CA), Marinus Inc. (Long Beach, CA), Pacific Bio-Marine (Venice, CA), and Sea Life Supply (Sand City, CA). Animals wcre houscd in individual perforated cages within a large aquarium containing aerated artificial seawater (ASW; Instant Ocean, Aquarium Systems, Mentor, $\mathrm{OH}$ ) maintained at $15^{\circ} \mathrm{C}$. Animals were exposed to a $12 \mathrm{hr} / 12 \mathrm{hr}$ light/dark cycle, and were fed an amount of dried seaweed sufficient to maintain a constant body weight.

Tissue collection and preparation of solutions. Tissue required to make solutions of bag cell extract (BCE) and abdominal ganglion extract (ABG) used in experiments 1 and 2 (see below) were collected from animals anesthetized by injection of volumes of isotonic $\mathrm{MgCl}_{2}$ equivalent to one-half of their body volume. Donor animals were not tested for sexual maturity (see below); however, primarily larger animals were used and in almost all cases the bag cells appeared to be fully developed. The abdominal ganglia, to which the bag cells are attached, were removed and pinned to the floor of a Sylgard (Dow-Corning)-lined chamber containing a solution of isotonic $\mathrm{MgCl}_{2} / \mathrm{ASW}(50 / 50, \mathrm{v} / \mathrm{v})$. The bag cell clusters, plus $2-5 \mathrm{~mm}$ of the pleural abdominal connectives, were then excised (Kupfermann, 1970). In order to collect the neurons of the abdominal ganglia for the preparation of the $\mathrm{ABG}$, the abdominal ganglia were then squeezed between a pair of forceps, forcing the neurons and neuropil out of the surrounding connective tissue. This method of isolating the neurons of the abdominal ganglion avoids contamination of the ABG with bag cell processes that permeate the connective tissue overlying the ganglion. The isolated bag cell clusters and abdominal ganglia exudate were stored $\left(-90^{\circ} \mathrm{C}\right)$ until sufficient tissue had been collected for the preparation of BCE and ABG solutions. ASW, used in the control solution and in the preparation of the experimental solutions, was buffered with $10 \mathrm{~mm}$ Tris (Trizma-7.6, Sigma, St. Louis, MO). BCE and $A B G$ were prepared by a modified protocol of that previously described (Strumwasser et al., 1969; Kupfermann, 1970; Arch and Smock, 1977). Briefly, BCE was prepared by thawing previously isolated bag cell clusters and homogenizing them on ice with 1 or $2 \mathrm{ml}$ of buffered ASW for approximately $5 \mathrm{~min}$ in a hand-held glass homogenizer. Sufficient buffered ASW was then added to the homogenate to arrive at a final concentration of the BCE solution that was equal to one pair of bag cell clusters per $1.3 \mathrm{ml}$. This volume of BCE is similar to that used previously and has been demonstrated to produce egg laying consistently (Strumwasser et al., 1969; Kupfermann, 1970; Arch and Smock, 1977; J. R. Goldsmith and J. H. Byrne, unpublished observation). ABG was prepared by thawing abdominal ganglia exudate and following a similar 
A

A $\square$ Sensitizing

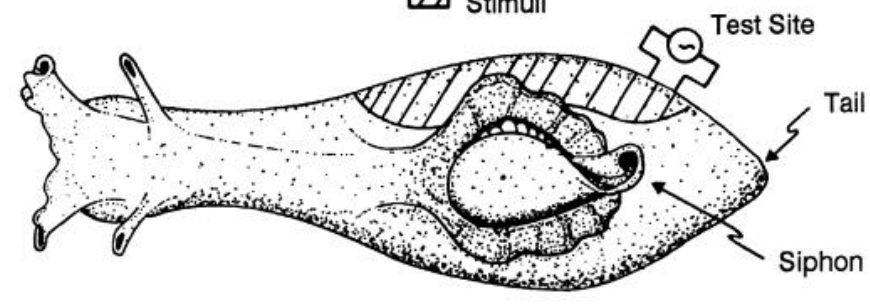

B Testing and Training Protocol

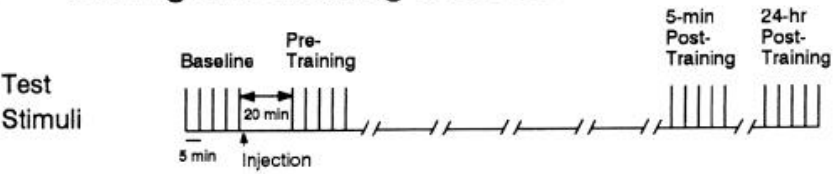

Sensitizing

Stimuli

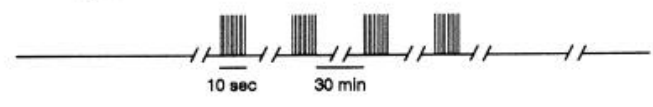

Figure 1. Diagram of testing and training protocol for behavioral experiments. $A$, Dorsal view of the animal detailing the area of the body wall that received the sensitizing stimuli and the area of the tail that received the test stimuli. $B$, Testing and training protocol. Testing consisted of four test periods: the baseline, pretraining, 5 min posttraining, and $24 \mathrm{hr}$ posttraining tests. Each of these 20 min test periods consisted of five stimuli delivered to the animal's tail at an ISI of $5 \mathrm{~min}$. The duration of the resulting siphon withdrawal was recorded. Immediately following the last stimulus in the baseline test period, the experimental or control solution was injected (see text) into the hemocoel via the anterior one third of the foot. Training consisted of four blocks of sensitizing stimuli, with each block delivered at an ISI of $30 \mathrm{~min}$ to the body wall (same side to which test stimuli were presented). Each training block consisted of a $10 \mathrm{sec}$ train of ten $500 \mathrm{msec}, 60 \mathrm{~mA} \mathrm{AC}$ pulses (1 $\sec$ ISI).

homogenization procedure (reaching a similar final concentration, i.e., one abdominal ganglion per $1.3 \mathrm{ml}$ ). Synthetic ELH (Peninsula Laboratories, Belmont, CA) was mixed on ice with buffered ASW $(15.9 \mu \mathrm{g}$ $\mathrm{ELH} / 1.3 \mathrm{ml} \mathrm{ASW}$; final concentration, $3 \mu \mathrm{M})$. The amount of ELH contained in this volume $(2.5 \mathrm{nmol})$ is similar to that used previously and consistently leads to egg laying (Chiu et al., 1979; Goldsmith and Byrne, unpublished observation). For comparison, the $1.3 \mathrm{ml}$ of BCE contains approximately $4.3-8.9 \mathrm{nmol}$ of ELH (Chiu et al., 1979). The protease inhibitor phenylmethylsulfonyl fluoride (Sigma; $10 \mathrm{~mm}$ ) was included in the preparation of the $\mathrm{ABG}$ and $\mathrm{BCE}$ solutions to retard the proteolytic degradation of the peptides contained in the extracts (Chiu et al., 1979) and was therefore also included in the preparation of the ASW and ELH solutions.

For experiments 2-4 (see below), ASW used in the control solution and in the preparation of the experimental solutions was buffered with 15 mM HEPES (Sigma). $\alpha-, \beta$-, and $\gamma$-BCP, ELH, and arginine vasotocin (ARG-VAS) were obtained from Peninsula Laboratories. BCE was prepared as described above. All solutions were aliquotted and stored at $-90^{\circ} \mathrm{C}$ until use.

Experiment 1: injection of $B C E$ and $E L H$; in vivo effects on the tailsiphon withdrawal reflex and sensitization of the reflex. All animals used in these experiments were maintained in an aquarium, separate from other animals. In order to ensure that the animals used in this study were reproductively mature (i.e., would lay eggs in response to an injection of $\mathrm{BCE}$ ), they were given an injection of $\mathrm{BCE}$ at least 1 week prior to the beginning of the experiment. Only those animals that laid eggs within a $2 \mathrm{hr}$ period were used. Experiments were carried out during the naturally occurring egg-laying season (June through December). After the $2 \mathrm{hr}$ period had elapsed, all animals that passed the reproductive maturity test were then parapodectomized. The parapodia, paired winglike extensions of the body wall that surround the mantle organs, were removed by reflecting them away from the mantle and excising along the line where they join the body wall. The parapodectomy and the implantation of electrodes (see below) were performed after the animal was partially anesthetized by placement in ice for several minutes.
One to three days prior to testing, a pair of Teflon-coated wire electrodes (type Ag 5T, Medwire, Mt. Vernon, NY) were implanted on each side of the animal's tail. The wire electrodes were implanted by first inserting a small portion of exposed wire (approximately $1 \mathrm{~cm}$ ) into the tip of a needle and then inserting the needle into the body wall, leaving the wire implanted in the musculature of the body wall as the needle was withdrawn.

On the day of testing, following a 30 min equilibration period, the threshold for siphon withdrawal was determined. Test stimuli were 30 msec duration AC shocks. The threshold intensity was that which reliably elicited a siphon withdrawal. The side that had the lower threshold was the side used for testing. The other side was not used further. Testing consisted of four 20 min periods, each consisting of five stimuli, delivered to the tail via the implanted electrodes, at an interstimulus interval (ISI) of 5 min (Fig. 1). The intensity of the stimuli was twice that of the threshold intensity. The threshold intensity was generally about $2 \mathrm{~mA}$. The duration of the siphon withdrawal was used as the measure of sensitivity of the animal to the test stimuli, and changes in the duration of the siphon withdrawal as a measure of sensitization and/or treatment effect. The duration of the siphon withdrawal was measured from the start of the contraction to the time the siphon reversed direction and began to relax to its prestimulus position. Although the tail and siphon components of the tail-siphon withdrawal reflex appear to track each other, these experiments were not performed using the tail component of the reflex due to the difficulty in obtaining accurate measurements of tail withdrawal in freely moving animals; however, preliminary experiments were performed using a semi-intact preparation in which the tail withdrawal was also examined (see below). All measures of duration of siphon withdrawal were performed by an observer blind to the experimental manipulations.

The first period of testing (baseline test) was begun $30 \mathrm{~min}$ after the determination of threshold. Animals were included in the study only if the mean of the five baseline test values was greater than $1 \mathrm{sec}$ and less than $10 \mathrm{sec}$. This procedure was followed to ensure that the animals were healthy and not previously sensitized. In addition, animals were not used if spontaneous egg laying had occurred during the previous 24 $\mathrm{hr}$. Immediately following the last stimulus in the baseline test period, $0.9 \mathrm{ml}$ of BCE, ELH, ABG, or vehicle (ASW) was injected into the hemocoel via the anterior one-third of the foot (Strumwasser et al., 1969).

The second period of testing (pretraining test) was begun $20 \mathrm{~min}$ after the injection. Immediately following the last stimulus in this period, the training procedure was begun. Training was essentially identical to that used previously (Scholz and Byrne, 1987), and consisted of four blocks of noxious stimuli, delivered once every $30 \mathrm{~min}$ to the body wall (same side to which test stimuli were presented) via a hand-held bipolar electrode (Fig. 1). Each training block consisted of a $10 \mathrm{sec}$ train of ten $500 \mathrm{msec}, 60 \mathrm{~mA}$ AC pulses (1 sec ISI). Training reliably elicited the release of ink and opaline, two defensive secretions released in response to noxious stimuli. The third period of testing ( $5 \mathrm{~min}$ posttraining test) and the fourth period of testing ( $24 \mathrm{hr}$ posttraining test) were begun 5 min after and $24 \mathrm{hr}$ after the last train of shocks, respectively. All experiments were performed at room temperature $\left(18-23^{\circ} \mathrm{C}\right)$, as this temperature falls within the range of temperatures Aplysia californica experience during the egg-laying season (Kupfermann and Carew, 1974).

A preliminary set of experiments were performed in which a semiintact preparation was used to measure the magnitude of the tail component of the reflex withdrawal in response to stimulation of the tail. Animals were anesthetized by injection of volumes of isotonic $\mathrm{MgCl}_{2}$ equivalent to one-half of their body volume. In these experiments, the viscera, body wall, and the majority of the nervous system were dissected from the animal, leaving only the left or right pleural-pedal ganglion, connected to the tail by peripheral nerve 9 (P9). The pleural-pedal ganglion was maintained in a separate chamber from the tail. The preparation was restrained with pins inserted through the most anterior regions of the tail. Wire electrodes used to elicit tail withdrawals were inserted into the tail. Prior to the beginning of each experiment, peripheral motility and reflex responses were restored by perfusing both chambers and the tail with ASW to remove excess $\mathrm{MgCl}_{2}$. Tail withdrawal was measured using a Grass FT.03B force-displacement transducer attached by surgical thread and a stainless steel hook to the tail. The tail withdrawal reflex was tested once every $5 \mathrm{~min}$. Two and onehalf minutes after the fifth test, $25 \mu \mathrm{l}$ of BCE or vehicle (ASW) was applied directly to the bath containing the pleural-pedal ganglion. The final bath concentration of $\mathrm{BCPs}$ (contained in $\mathrm{BCE}$ ) was estimated to 

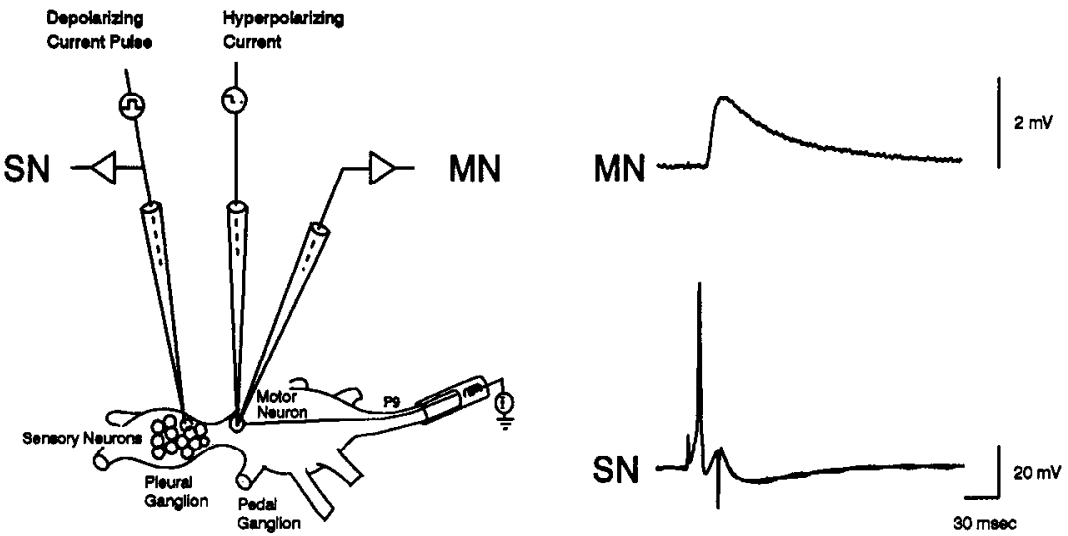

B Testing Protocol

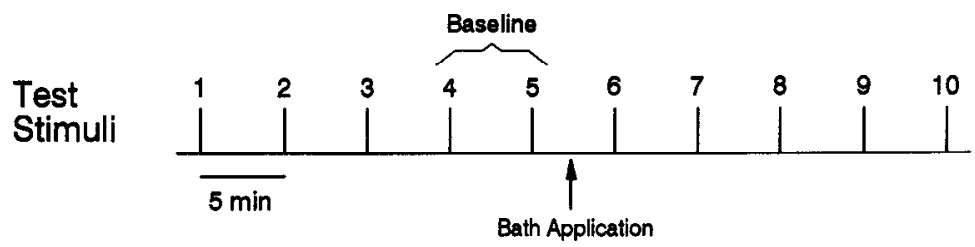

Figure 2. Diagram of the in vitro preparation and testing protocol for electrophysiological experiments. $A$, The in vitro preparation. Illustrated on the left panel is the isolated pleural-pedal ganglion with peripheral nerve $\mathrm{P} 9$ mounted in a suction electrode. Tail motor neurons were positively identified by passing current $(I)$ through the suction electrode to determine whether the neuron had an axon in the peripheral nerve. A single microelectrode was used to stimulate and record from the sensory neuron $(S N)$ in the pleural ganglion, whereas separate electrodes were used to hyperpolarize and record from the motor neuron $(M N)$ in the pedal ganglion. The right panel illustrates representative traces, obtained during testing, from both a sensory neuron and motor neuron. An action potential elicited in a sensory neuron by a suprathreshold depolarizing pulse produces a short-latency monosynaptic EPSP in the motor neuron. $B$, Testing protocol. Testing was composed of 10 test stimuli (trials) delivered at an ISI of $5 \mathrm{~min}$. Each test consisted of cliciting a singlc action potential in a tail sensory ncuron with a suprathreshold depolarizing current pulse and recording the monosynaptic EPSP elicited in the follower tail motor neuron. Two and one-half minutes following the fifth stimulus, the experimental or control solution was applied to the bath. The value of each trial was normalized to the mean of the two trials preceding the bath application [trials 4 and 5 (baseline)].

be $1 \mu \mathrm{M}$. The reflex withdrawal of the tail was then monitored for five more tests.

Experiment 2: bath application of BCE; in vitro effects on synaptic strength. Animals were anesthetized by injection of volumes of isotonic $\mathrm{MgCl}_{2}$ equivalent to one-half of their body volume. The left pleuralpedal ganglion, as well as peripheral nerve $P 9$, were removed and placed in a Sylgard-lined recording chamber containing a solution of isotonic $\mathrm{MgCl}_{2} / \mathrm{ASW}(50 / 50, \mathrm{v} / \mathrm{v})$. The bulk of the connective tissue overlying the pleural-pedal ganglion was surgically removed. Upon completion of the dissection, the ganglion was firmly pinned and nerve P9 was drawn into a suction electrode (Fig. 2). The 50/50 solution was then exchanged at least five times with ASW to ensure the removal of excess $\mathrm{MgCl}_{2}$.

Tail sensory neurons and motor neurons were impaled with glass capillary microelectrodes (4-6 M $\Omega$ ) filled with 3 м K-acetate (Fig. 2A). Sensory neurons were impaled with a single microelectrode for recording and stimulating. Motor neurons were impaled with two microelectrodes, one for recording and one for current injection. Tail sensory neurons, located in the pleural ganglion, were identified by their location, size, and electrophysiological properties. Tail motor neurons, located in the pedal ganglion, were identified superficially by their location, size, spontaneous EPSPs and IPSPs, and more precisely by their resting membrane potential, synaptic input from the sensory neurons, and antidromic activation by stimulation of nerve P9 (which contains the axon of the motor neuron).

Tail motor neurons were used as the follower cells since it is more feasible to monitor the connections between sensory neurons and their large and readily identifiable follower tail motor neurons than the connections between the sensory neurons and their smaller and more difficult to identify follower interneurons that relay the tail sensory information to siphon motor neurons. It is the monosynaptic connection between the tail sensory neurons and these motor neurons that mediates the tail component of the tail-siphon withdrawal reflex. Plasticity at this synapse correlates with changes in the tail component of the reflex (Walters et al., 1983b). In addition, preliminary evidence from our laboratory (Y. Xu, L. J. Cleary, and J. H. Byrne, personal communication) indicates that plasticity of the sensory neuron-to-tail motor neuron and sensory neuron-to-interneuron connections are similar. Standard electrophysiological techniques were used to make intracellular recordings from sensory neurons and motor neurons. Experiments were conducted at room temperature $\left(18-23^{\circ} \mathrm{C}\right)$.

Testing consisted of 10 test stimuli (trials) delivered at an ISI of 5 min (Fig. $2 B$ ). Trials $1-5$ and 6-10 were analogous to the first two test periods in the behavioral experiments, respectively. Each test consisted of eliciting a single action potential in the sensory neuron with a 30 msec suprathreshold depolarizing pulse and recording the monosynaptic EPSP elicited in the motor neuron. Two and one-half minutes following the fifth stimulus, $25 \mu 1$ of BCE or vehicle (ASW) was applied to the bath. The final bath concentration of BCPs (contained in BCE) was estimated to be $1 \mu \mathrm{M}$. Motor neurons were hyperpolarized by approximately $30 \mathrm{mV}$ during each test stimulus to prevent the EPSP evoked by the sensory neuron from triggering an action potential in the motor neuron. Measurements of input resistance of the motor neuron (while the cell was hyperpolarized) were made by injecting $1 \mathrm{sec}, 1 \mathrm{nA}$ hyperpolarizing pulses into the motor neuron.

Experiment 3: hath application of BCPs; in vitro effects on synaptic strength. The procedures of this experiment were identical to those of experiment 2. In addition to examining the effects of $\alpha-\beta-$, and $\gamma-\mathrm{BCP}$ and ELH, arginine vasotocin (ARG-VAS) was included to examine whether it could attenuate sensory-to-motor neuron synapses in the pleural-pedal ganglion as had been previously demonstrated in the abdominal ganglion (Goldberg et al., 1987). Final bath concentrations of all peptides was $1 \mu \mathrm{M}$. This concentration has been used previously and leads to autoexcitation of the bag cells $(\alpha-, \beta-$, and $\gamma-\mathrm{BCP}$; Brown and Mayeri, 1989), prolonged excitation of LB and LC cells, and burst augmentation of cell R15 (ELH; Mayeri et al., 1985), as well as to 


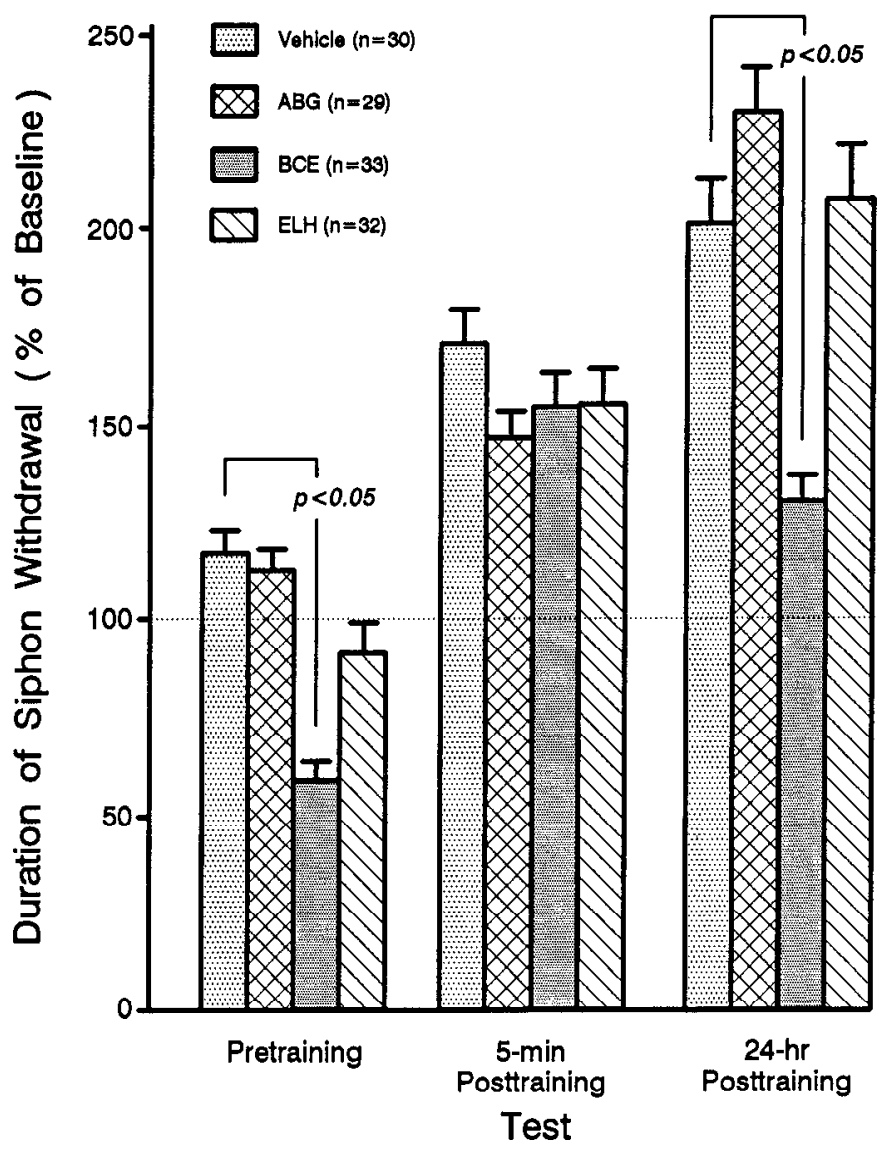

Figure 3. Effects of BCE on the tail-siphon withdrawal reflex. The mean durations ( \pm SEM) of the siphon withdrawal in response to stimulation of the tail for each test period (normalized to the baseline test period) are illustrated. Injection of BCE significantly inhibited the tailsiphon withdrawal reflex $(58.9 \pm 4.5 \%$ of baseline) and significantly suppressed long-term sensitization of the reflex (130.1 $\pm 6.4 \%$ of baseline), while leaving short-term sensitization unaltered.

suppression of sensory-to-motor connections in the abdominal ganglion (ARG-VAS; Goldberg et al., 1987).

Experiment 4: bath application of $\beta-B C P$; in vitro effects on synaptic strength and presynaptic spike duration. The procedures of this experiment were identical to those of experiment 2 except for the following. (1) The ganglia were rinsed prior to dissection in a mixture of ASW and isotonic $\mathrm{MgCl}_{2}$ containing $0.5 \%$ glutaraldehyde (Sigma) for $50 \mathrm{sec}$ in order to reduce tetraethylammonium chloride (TEA)-induced contractions in the connective tissue sheath (Mirolli and Gorman, 1968; Byrne et al., 1979). (2) The bath contained $100 \mathrm{~mm}$ TEA (Eastman Kodak, Rochester, NY) to facilitate detection of changes in duration of the action potential, and low $\mathrm{Na}^{+}(108 \mathrm{~mm})$ to reduce spontaneous synaptic activity. $\mathrm{Na}^{+}$was replaced with equimolar amounts of $N$-methyl-Dglucamine [Sigma; $\mathrm{pH}$ adjusted to 7.6 with concentrated hydrochloric acid (Kirk et al., 1988)]. (3) To avoid distortion of the action potential in the sensory neuron by the bridge circuit artifact, a short depolarizing pulse of $1.5 \mathrm{msec}$ was used to elicit the spike. (4) The final bath concentration of $\beta$-BCP ranged from 1 to $10 \mu \mathrm{M}$.

Data and statistics. Electrophysiological data were stored on a VCR tape recorder, and permanent records were made with a Gould model 2400 pen recorder. The half-amplitude spike duration (duration from the peak of the spike to $50 \%$ of its repolarization to the resting potential) in the sensory neuron, and the peak amplitude, slope of the rising phase (measured from a point $20 \%$ above baseline to a point $20 \%$ below peak amplitude), and time to peak (time from the beginning of the rising phase to the peak of the EPSP) of the EPSP in the motor neuron were measured using a computer program.

In experiment 1 , the mean test score in each test period for each animal was calculated and was then normalized to the animal's baseline test score. A logarithmic transformation was then performed on each normalized value $(X)$, using the equation $X^{\prime}=\log (X+1)$ (Howell, 1987). This transformation ensured homogeneity in variances for each group. A two-tailed two-way analysis of variance (ANOVA) with repeated measures on one factor was then performed, followed by twotailed Dunnett's tests comparing each experimental group to control at each of the three test periods.

In experiments $2-4$, the value of each trial was normalized to the mean of the two trials preceding the bath application [trials 4 and 5 (baseline)]. All data, with the exception of measurements of membrane potential, were analyzed using two-way ANOVAs with repeated measures on the normalized values from trials $6-10$. Where appropriate, a Dunnett's test was used for post hoc examination of main or simple effects. As per Dunnett (1955; referenced in Zar, 1984), the control group in experiment 3 contained approximately 2.2 times as many experiments as each other group. Changes in membrane potential of the sensory neuron and motor neuron were analyzed by normalizing the resting potential of the neuron at the end of the experiment to the measurement at the beginning of the experiment and then performing a Student's $t$ test or one-way ANOVA to compare the differences between treatments. Two-tailed statistical analyses were performed on the initial experiments examining the effects of BCE. Thereafter, one-tailed analyses were used since the results from the behavioral experiments and the preliminary electrophysiological experiments with bath-applied BCE suggested that the BCPs attenuate synaptic strength. Data in the text and figures are expressed in terms of the mean \pm SEM. For all statistical tests a $p<$ 0.05 was considered significant.

\section{Results}

Experiment 1

The purpose of this experiment was to examine whether the BCPs exert any effects on the tail-siphon withdrawal reflex and short- and long-term sensitization of the reflex. To address this issue, BCE was administered to one group of animals. ELH, which has been demonstrated to elicit egg laying (Stuart et al., 1980; Strumwasser, 1984; Strumwasser et al., 1987), was administered to a second experimental group to determine if it, in the absence of other components of BCE, had any effects on the tail-siphon withdrawal reflex and/or sensitization of the reflex. Another group received an extract of the abdominal ganglion minus the bag cell clusters (ABG). This treatment was necessary since an effect of the BCE could be due to some factor or factors in the BCE unrelated to the BCPs. A control group received injections of the vehicle.

A two-way ANOVA revealed that there was a significant difference in the duration of the siphon withdrawal between treatment groups $[F(3,120)=3.46]$. In addition, there was also a significant enhancement in the duration of the siphon withdrawal produced by the sensitization training $[F(2,240)=30.55$; $p<0.001]$. There was an absence of an interaction effect $[F(6,240)$ $=1.54]$. The mean duration $( \pm$ SEM) of the siphon withdrawal in the basclinc test was, respectively, $4.1 \pm 0.4 \mathrm{sec}(n=30)$, $5.0 \pm 0.5 \sec (n=29), 4.1 \pm 0.4 \sec (n=33)$, and $4.3 \pm 0.4$ $\sec (n=32)$ for the control, ABG, BCE, and ELH groups. The mean duration $( \pm$ SEM) of siphon withdrawal (mean of each test period normalized to the baseline test period) is illustrated in Figure 3.

$B C E$ significantly inhibited the tail-siphon withdrawal reflex. The mean duration of the siphon withdrawal (measured at the pretraining test) in the BCE group was markedly reduced relative to the baseline test $(58.9 \pm 4.5 \%)$ (Fig. 3). BCE inhibited the siphon withdrawal in each of the trials after the injection, beginning with trial 1 (data not shown). A Dunnett's test revealed that the duration of the siphon withdrawal in the BCE group was significantly different from the duration of the withdrawal in the group that received the vehicle (116.8 $\pm 5.9 \%$ of baseline) $[q(120)=2.70]$. ABG- and ELH-treated animals were not sig- 
nificantly different than control $(112.3 \pm 5.4 \%$ and $91.4 \pm 7.9 \%$ of baseline, respectively). Egg laying in all BCE- and ELH-treated animals was observed to begin at or after the third trial of the pretraining test period. No egg laying was observed in animals in the ABG or control group.

The baseline tail withdrawal reflex also appeared to be inhibited by BCE in preliminary experiments using a semi-intact preparation in which the tail withdrawal was measured. The tail withdrawal was $86 \%$ of baseline after application of ASW $(n=$ 6 ), whereas in experiments in which BCE was applied the withdrawal was $70 \%$ of baseline $(n=7)$. These data suggest that BCE may inhibit both components of the tail-siphon withdrawal reflex similarly.

Short-term sensitization was unaffected by any of the experimental treatments. The sensitization training produced a shortterm enhancement of the duration of the siphon withdrawal in all groups, which was unaffected by any of the experimental treatments. The degree of enhancement of the duration of the siphon withdrawal (measured at the $5 \mathrm{~min}$ posttraining test) in the ABG, BCE, and ELH groups $(146.0 \pm 6.7 \%, 154.1 \pm 8.1 \%$, and $154.7 \pm 8.6 \%$ of baseline) was similar to the enhancement observed in the group that received the vehicle $(170.4 \pm 8.1 \%$ of baseline) (Fig. 3). The lack of any effects on short-term sensitization by the ABG, BCE, or ELH treatments was confirmed by a Dunnett's test that revealed no significant differences between any of the experimental treatments and control at the 5 min posttraining test.

$B C E$ significantly suppressed long-term sensitization. The longterm effects of the sensitization training, assessed $24 \mathrm{hr}$ later, consisted of a further enhancement of the duration of the siphon withdrawal in all of the treatment groups except BCE, in which long-term sensitization of the reflex was considerably suppressed (130.1 $\pm 6.4 \%$ of baseline) (Fig. 3). The duration of the siphon withdrawal in the vehicle, ABG, and ELH treatment groups was $201.3 \pm 12.2 \%, 229.6 \pm 11.2 \%$, and $207.6 \pm 13.0 \%$ of baseline, respectively. The long-term enhancement in the duration of siphon withdrawal in the BCE-treated animals was less than the enhancement observed in the 5 min posttraining test period. A Dunnett's test comparing each treatment to control at the $24 \mathrm{hr}$ posttraining test indicated that the suppression of long-term sensitization by the BCE treatment was significant $[q(120)=$ 2.34].

The following series of electrophysiological experiments were performed to examine whether the BCPs modulate elements of the circuitry underlying the reflex.

\section{Experiment 2: BCE significantly attenuated synaptic strength}

Experiments using an in vitro analog of the tail component of the reflex were performed in order to examine whether the circuitry underlying the reflex was a locus of action of the BCE. In these experiments we examined the tail sensory-to-motor neuron connection, which underlies the tail component of the tail-siphon withdrawal reflex. Sensory neurons were stimulated at an ISI of $5 \mathrm{~min}$. The mean amplitude $( \pm$ SEM) of the baseline EPSP was $5.6 \pm 2.0 \mathrm{mV}(n=3)$ and $4.5 \pm 1.4 \mathrm{mV}(n=5)$ in the control and BCE experiments, respectively. Homosynaptic depression, a reduction in synaptic strength due to repetitive activation of the sensory neuron, was observed in both the experimental and control group. However, the amplitudes of the EPSPs following bath application of BCE were dramatically attenuated relative to the EPSPs in the experiments in which the vehicle was bath applied (i.e., trial 10: $45.2 \pm 3.4 \%$ vs 79.3

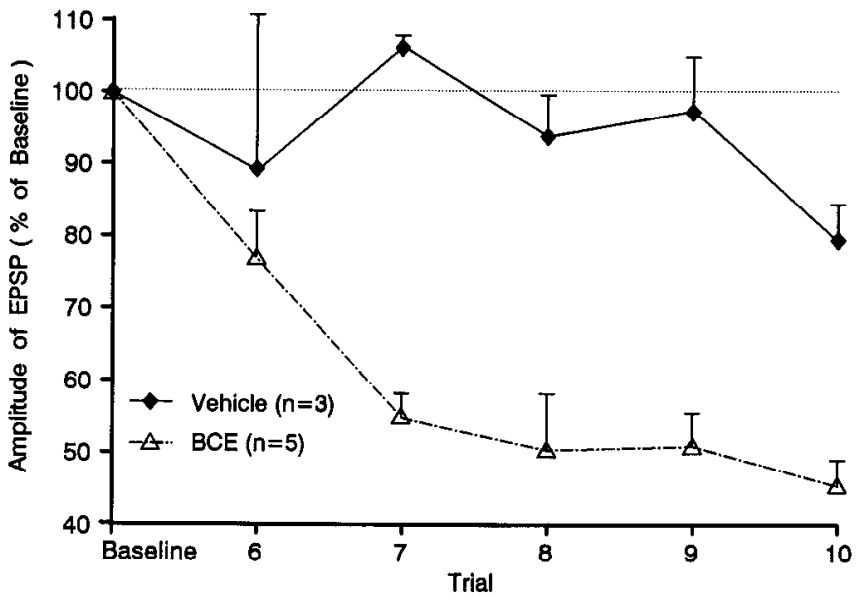

Figure 4. Effects of BCE on the amplitude of the EPSP. The mean amplitudes $( \pm$ SEM) of the EPSP for trials $6-10$ [normalized to baseline (mean of trials 4 and 5)] are illustrated. Bath application of BCE significantly attenuated the amplitude of the EPSP.

$\pm 4.9 \%$ of baseline, respectively) (Fig. 4). A two-way ANOVA with repeated measures indicated that the attenuation produced by $\mathrm{BCE}$ was significant $[F(1,6)=44.37 ; p<0.005]$. There were no significant differences between treatments in the membrane potential of the sensory neurons $\left(t_{6}=1.902\right)$ or motor neurons $\left(t_{6}=0.131\right)$, nor was there any difference between the measurements of input resistance $[F(1,6)=3.166]$. Thus, BCE significantly attenuates the synaptic strength of the connection between sensory neurons and their follower cells.

In the next series of electrophysiological experiments, the actions of the individual BCPs were examined independently.

\section{Experiment 3: $\beta-B C P$ significantly attenuated synaptic strength}

This series of experiments was designed to determine which of the BCPs contained in the BCE may mediate the modified behavior and attenuated synaptic strength observed after application of BCE, and to provide insight into the possible site(s) and mechanism(s) of action. The mean amplitude ( \pm SEM) of the baseline EPSP in each group was $6.1 \pm 1.2 \mathrm{mV}$ (vehicle; $n$ $=17), 6.7 \pm 1.1 \mathrm{mV}(\alpha$-BCP; $n=8), 3.5 \pm 0.7 \mathrm{mV}$ (ARGVAS; $n=8), 7.3 \pm 2.5 \mathrm{mV}(\beta$-BCP; $n=8), 8.3 \pm 2.6 \mathrm{mV}$ (ELH; $n=8)$, and $4.4 \pm 1.6 \mathrm{mV}(\gamma$-BCP; $n=8)$.

In at least one of the experimental groups, $\beta$ - $\mathrm{BCP}$, the amplitudes of the EPSPs were attenuated beyond that expected from depression alone. Representative traces of EPSPs produced in the motor neuron (MN) by action potentials elicited in the sensory neuron (SN) from an experiment with $\beta$-BCP as well as from a control experiment are shown in Figure 5. The change in the amplitude of the EPSP between trials 4 and 5 and trials 9 and 10 in the control experiment (Fig. $5 A 1, A 2$, respectively) reflects depression of the synapse with repeated stimulation. In contrast, the change in the amplitude of the EPSP over the same period of time in the $\beta$-BCP experiment (Fig. $5 B 1, B 2$, respectively) reflects an attenuation of synaptic strength greater than that expected from depression alone. Summary data from all experiments are shown in Figure 6. For display purposes, $\beta$-BCP, the only peptide that produced a significant effect (see below), has been displayed independently (Fig. 6A) of the other peptides (Fig. 6B).

A two-way ANOVA with repeated measures indicated that 
A1 ASW

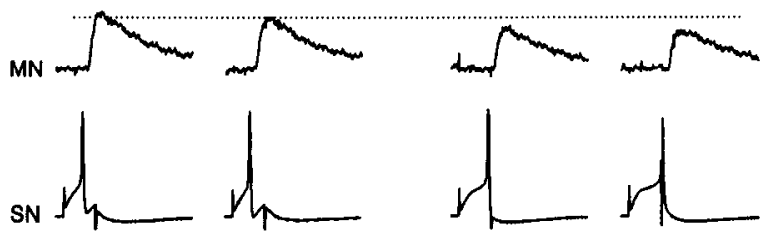

B1 ASW

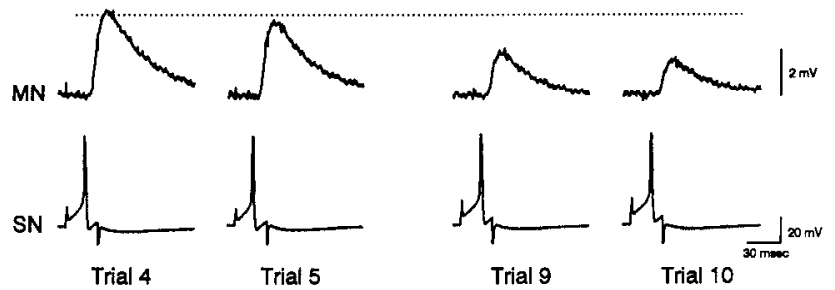

Figure 5. Effect of $\beta$-BCP on the amplitude of the EPSP: representative traces. EPSPs produced in the motor neuron $(M N)$ by action potentials elicited in the sensory neuron $(S N)$ from a control (vehicle) and $\beta$-BCP experiment are illustrated. The broken lines indicate the amplitude of the baseline EPSP (mean of trials 4 and 5). $A$, In this example from a control experiment, the amplitude of the EPSP in trial 9 and 10 was $70 \%$ and $74 \%$ of baseline, respectively. This change reflects depression of the synapse with repetitive stimulation. $B$, In this example from a $\beta$-BCP experiment, the amplitude of the EPSP in trial 9 and 10 was $53 \%$ and $44 \%$ of baseline, respectively. This change reflects an attenuation of the synaptic strength produced by $\beta$-BCP that is beyond that expected from depression alone.

there was a significant difference between treatments $[F(5,51)$ $=2.86 ; p<0.025]$. A test of main effects (a Dunnett's test comparing the five experimental treatments to control) revealed that only the attenuation produced by $\beta$-BCP was significant $[q(51)=2.70]$. Bath application of $\alpha-\mathrm{BCP}, \gamma-\mathrm{BCP}, \mathrm{ELH}$, or ARG-VAS failed to attenuate the connection significantly. By trial 10, the amplitudes of the EPSPs in the $\beta$-BCP experiments were attenuated to $39.8 \pm 4.6 \%$ of baseline whereas the amplitude of the EPSPs in the control experiments were $74.7 \pm$ $6.6 \%$ of baseline. There were no significant differences between treatments in the membrane potential of the sensory neuron or motor neuron $[F(5,40)=0.48$ and $F(5,40)=0.31$, respectively].

There was, however, a significant decrease in the input resistance of the motor neuron in the $\beta$ - $\mathrm{BCP}$ experiments. A twoway ANOVA with repeated measures performed on the input resistance of the motor neuron revealed a significant interaction effect $[F(20,204)=2.052]$. Subsequent Dunnett's tests for simple effects indicated that the input resistance measurements for the control and $\beta$-BCP experiments were significantly different $[q(51)$ $=2.47]$ at trial $10(93.5 \pm 6.3 \%$ and $75.0 \pm 6.0 \%$ of baseline, respectively). This decrease in input resistance could contribute to the attenuation of synaptic strength produced by $\beta$-BCP at this trial.

In the present experiments, which were conducted in ASW, there did not seem to be any effect of $\beta$-BCP on spike duration; however, a decrease in $I_{\mathrm{Ca}}$ or an increase in $I_{\mathrm{K}, S}$, either of which may be important in the modulation by $\beta$-BCP (and cause spike narrowing and thus decreased release of transmitter), would not easily be detected in these experiments.

The next set of experiments specifically examined whether the attenuation of synaptic strength produced by $\beta$-BCP could be due, at least in part, to presynaptic spike narrowing.

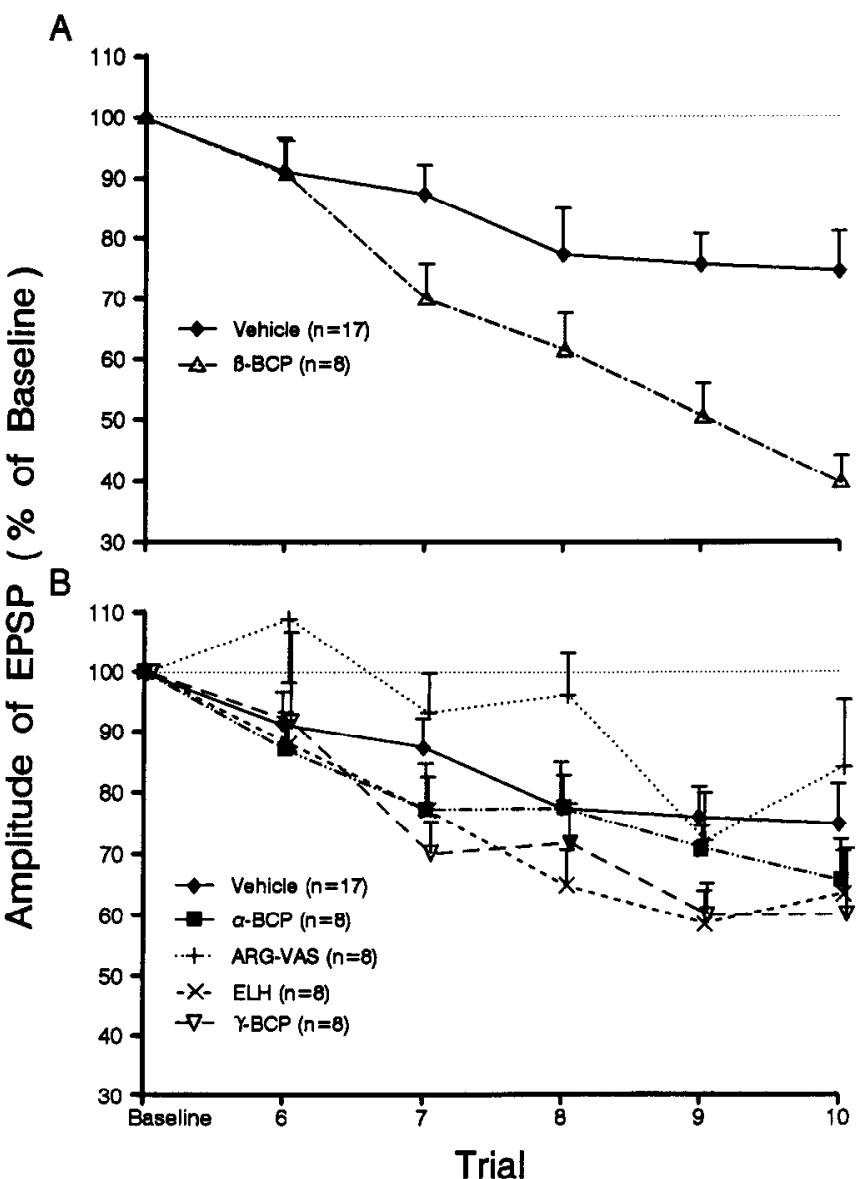

Figure 6. Effects of BCPs on the amplitude of the EPSP. Bath application of $\beta$-BCP significantly attenuated the amplitude of the EPSP. For display purposes, $\beta$-BCP, the only peptide that produced a significant effect, has been displayed independently $(A)$ of those peptides that did not $(B)$. $\beta$-BCP significantly attenuated the amplitude of the EPSP beginning $7.5 \mathrm{~min}$ after (trial 7) its bath application. The mean amplitude $( \pm$ SEM) of the EPSP for trials 6-10 [normalized to baseline (mean of trials 4 and 5)] are illustrated.

Experiment 4: significant attenuation of synaptic strength produced by $\beta-B C P$ is not dependent on presynaptic spike narrowing

To address whether $I_{\mathrm{Ca}}$ or $I_{\mathrm{K}, S}$ may be affected by $\beta$-BCP, the present experiments were performed in ASW containing 100 mM TEA and low $\mathrm{Na}^{+}$. TEA has previously been shown to block both $I_{\mathrm{K}, V}$ and $I_{\mathrm{K}, \mathrm{Ca}}$ in pleural sensory neurons (Baxter and Byrne, 1989; Walsh and Byrne, 1989). Under these circumstances the resultant action potential is significantly broadened and is due primarily to $I_{\mathrm{Ca}}$ (for polarization) and $I_{\mathrm{K}, s}$ (for repolarization). Moreover, small changes in $I_{\mathrm{Ca}}$ or $I_{\mathrm{K}, s}$ can have profound effects on the duration of the action potential. Thus, by using this protocol, which facilitates the ability to detect changes in spike duration, we can determine to what extent the modulation of $I_{\mathrm{Ca}}$ or $I_{\mathrm{K}, S}$ may be correlated with the attenuation of synaptic strength produced by $\beta-\mathrm{BCP}$.

Representative examples from a control (vehicle) and $\beta$-BCP experiment are shown in Figure $7 A$. In this figure the EPSPs produced in the motor neuron (MN) by a TEA-broadened spike elicited in the sensory neuron (SN) are illustrated for the test 2.5 min before (trial 5) and 22.5 min after (trial 10) bath application of vehicle (Fig. 7A1) or $\beta$-BCP (Fig. 7A2). In this 

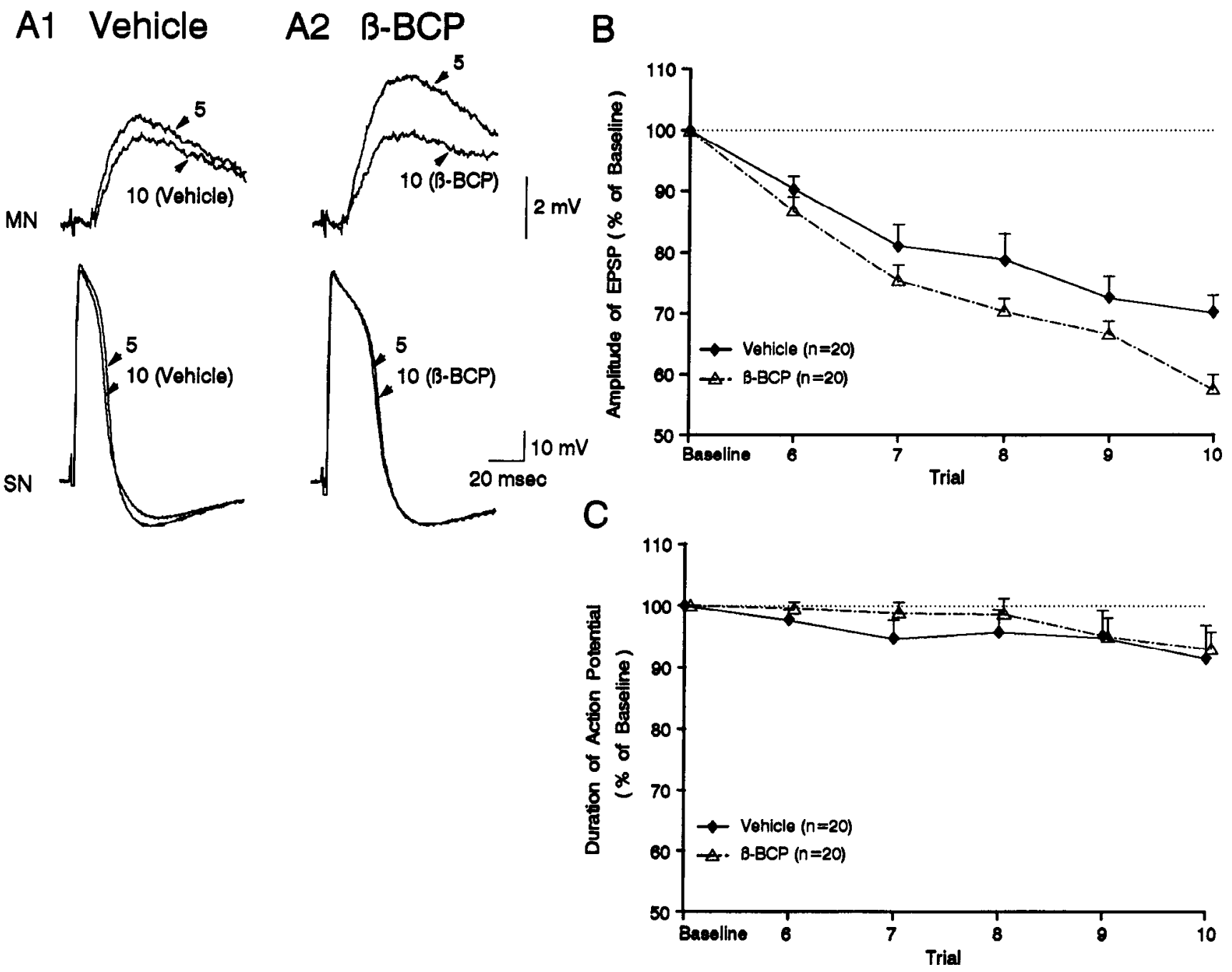

Figure 7. Effect of $\beta$-BCP on the amplitude of the EPSP and the duration of the presynaptic action potential. The attenuation of synaptic strength produced by $\beta$-BCP is not dependent on presynaptic spike narrowing. $A$, Representative traces of FPSPs produced in the motor neuron ( $M N)$ by a TEA-broadened action potential elicited in the sensory neuron $(S N) 2.5 \mathrm{~min}$ before (trial 5) and $22.5 \mathrm{~min}$ after (trial 10) bath application of vehicle or $\beta$-BCP. $A 1$, The amplitude of the EPSP $2.5 \mathrm{~min}$ prior to application of the vehicle (5) was $3.4 \mathrm{mV}$ and depressed to $2.8 \mathrm{mV} 22.5 \mathrm{~min}$ later $[10$ (vehicle $)]$. The duration of the spike was $15.6 \mathrm{msec}$ and $13.5 \mathrm{msec}$, respectively. $A 2$, The amplitude of the EPSP $2.5 \mathrm{~min}$ prior to application of $\beta$-BCP (5) was $4.8 \mathrm{mV}$ and was $2.8 \mathrm{mV} 22.5 \mathrm{~min}$ after adding $\beta$-BCP [ $10(\beta-B C P)$ ]. The duration of the spike was $22.5 \mathrm{msec}$ and $24.6 \mathrm{msec}$, respectively. $\beta-\mathrm{BCP}$, in this example, dramatically attenuated the amplitude of the EPSP even though the duration of the action potential was slightly greater after application of the peptide than before. $B, \beta$-BCP significantly attenuated the amplitude of the EPSP. The mean amplitudes $( \pm$ SEM) of the EPSP for trials 6-10 [normalized to baseline (mean of trials 4 and 5)] are illustrated. $C$, The modulation of synaptic strength produced by $\beta$-BCP was not accompanied by a significant narrowing of the presynaptic action potential. The mean durations ( \pm SEM) of the action potential for trials 6-10 [normalized to baseline (mean of trials 4 and 5)] are illustrated.

example, $\beta$-BCP dramatically attenuated the amplitude of the EPSP even though there was little or no change in the duration of the action potential. Indeed, the duration of the action potential was slightly greater after application of the peptide than before.

Summary data are shown in Figure $7 B$. The mean amplitude ( \pm SEM) of the baseline EPSP in the control and $\beta$-BCP experiments was $3.7 \pm 0.5 \mathrm{mV}(n=20)$ and $5.8 \pm 0.8 \mathrm{mV}(n=20)$, respectively. There was no significant difference between control and $\beta$-BCP groups in the mean amplitude of the initial EPSP (trial 1: $6.2 \pm 0.9 \mathrm{mV}, n=20$, and $8.6 \pm 1.2 \mathrm{mV}, n=20$, respectively; $t_{38}=1.620$ ) or in the rate of depression prior to the bath application (trial 5 normalized to trial $1: 58.8 \pm 2.7 \%$, $n=20$, and $64.5 \pm 3.1 \%, n=20$, respectively; $\left.t_{38}=1.407\right)$. $\beta$-BCP produced an attenuation of synaptic strength beginning
$2.5 \mathrm{~min}$ after bath application that lasted for at least $22.5 \mathrm{~min}$. By trial 10, the amplitudes of the EPSPs in the $\beta$-BCP experiments were attenuated to $57.5 \pm 2.4 \%$ of baseline whereas the amplitudes of the EPSPs in the control experiments, in which the vehicle was applied, were $70.1 \pm 2.9 \%$ of baseline (Fig. $7 B$ ). A two-way ANOVA with repeated measures indicated that the attenuation of the amplitude of the EPSP produced by $\beta$-BCP was significant $[F(1,38)=5.049]$.

Interestingly, this modulation of synaptic strength was not accompanied by a pronounced narrowing of the presynaptic action potential $[F(1,38)=0.261]$ (Fig. $7 C$ ). Indeed, the duration of the action potential remained relatively constant in both the control and $\beta$-BCP experiments, decreasing to $91.6 \pm 5.1 \%$ and $92.9 \pm 2.9 \%$ of baseline, respectively, by trial 10 (Fig. $7 \mathrm{C}$ ). The mean duration $( \pm \mathrm{SEM})$ of the baseline spike was $22.8 \pm$ 


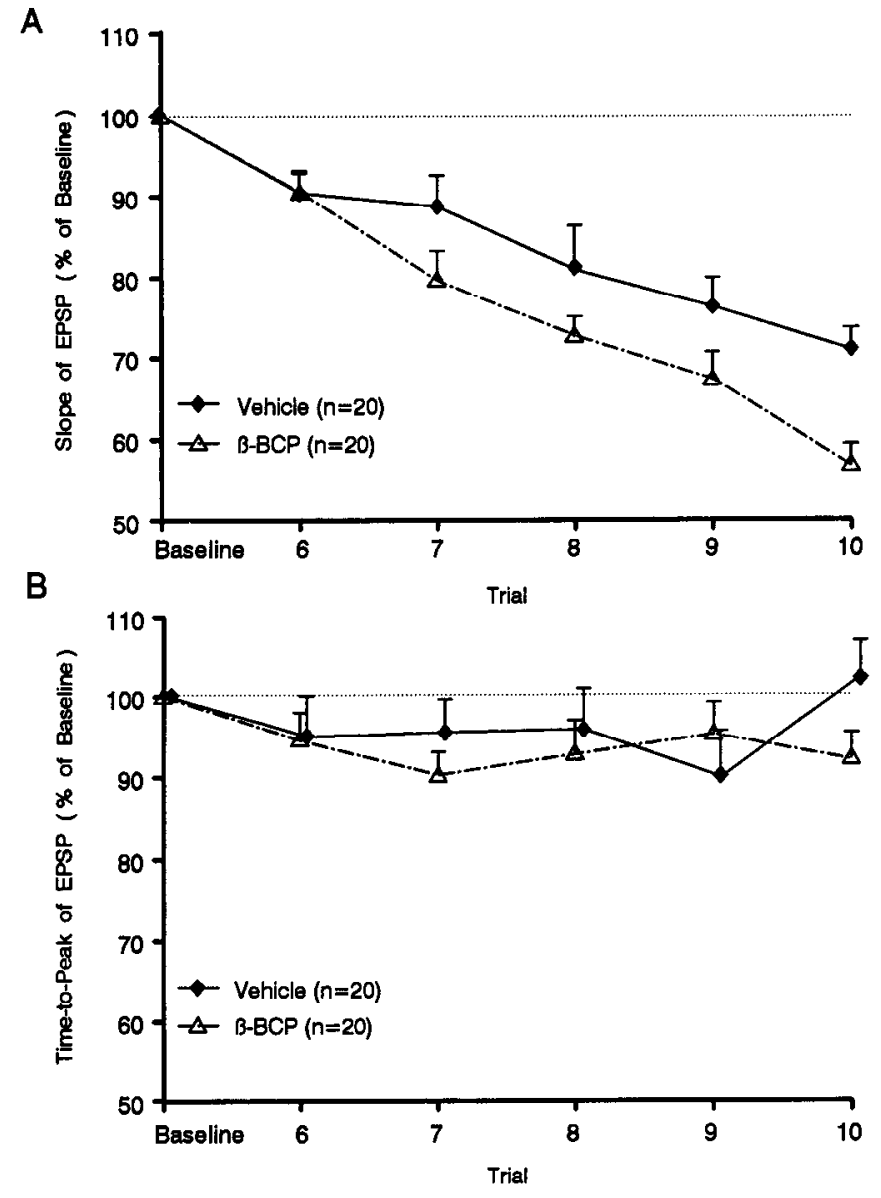

Figure 8. Effect of $\beta-\mathrm{BCP}$ on the slope and time to peak of the EPSP. The mean slope and time to peak of the EPSP for each of the post-bath application trials [normalized to baseline (mean of trials 4 and 5)] are illustrated. The attenuation of synaptic strength produced by $\beta-\mathrm{BCP}$ is accompanied by a significant decrease in slope, but not a significant decrease in time to peak. $A, \beta-\mathrm{BCP}$ significantly attenuated the slope of the EPSP. $B$, In contrast to the effect on the slope of the EPSP, $\beta$-BCP did not significantly affect the time to peak of the EPSPs.

$2.5 \mathrm{msec}$ (vehicle; $n=20)$ and $21.0 \pm 1.5 \mathrm{msec}(\beta-\mathrm{BCP} ; n=$ 20).

Previous empirical and modeling studies on the mechanisms underlying presynaptic facilitation (Hochner et al., 1986; Gingrich et al., 1988) indicate that changes in the duration of the presynaptic action potential are accompanied by changes in the time to peak of the EPSP in the follower neuron, whereas a spike duration-independent (SDI) process(es) (see also Pieroni and Byrne, 1992), such as changes in aspects of the transmitter release mechanisms (e.g., mobilization of transmitter) of the sensory neuron, are accompanied by changes in the slope of the EPSP. Assuming that similar correlations exist for forms of presynaptic plasticity other than facilitation, the shape of the EPSP in the motor neuron was analyzed.

Consistent with the fact that $\beta$-BCP did not produce a significant decrease in the duration of the action potential, there was no significant difference between $\beta$-BCP and control in the time to peak of the EPSP $[F(1,38)=0.464]$ (Fig. $8 B)$. By trial 10 , the times to peak of the EPSPs in the $\beta$-BCP and control experiments were $92.2 \pm 3.2 \%$ and $102.5 \pm 4.6 \%$ of baseline, respectively. In contrast, there was a significant difference between $\beta$-BCP and control in the slope of the EPSP $[F(1,38)=$
6.722] (Fig. 8A). This effect seemed to parallel the changes in the amplitude of the EPSP. By trial 10, the slopes of the EPSPs in the $\beta$-BCP experiments were attenuated to $56.8 \pm 2.7 \%$ of baseline, whereas the slopes of the EPSPs in the control experiments were $71.0 \pm 2.8 \%$ of baseline (Fig. $8 A$ ). This would suggest that $\beta$-BCP acts, at least in part, to modulate aspects of the transmitter release mechanisms.

There were no significant differences between treatments in the membrane potential of the sensory neuron $\left[t_{38}=1.162\right]$ or motor neuron $\left[t_{38}=1.962\right]$ or in the measurements of input resistance $[F(1,38)=0.077]$.

\section{Discussion}

$B C E$ inhibits tail-siphon withdrawal reflex

These results suggest that one or more of the peptides contained in the BCE, and released at the time of egg laying, are capable of significantly inhibiting the baseline tail-siphon withdrawal reflex. Thus, in addition to the role the BCPs play in initiating egg laying and in eliciting the behaviors preceding and accompanying egg laying, they may also serve to modulate the animals response to external stimuli during egg laying. Inhibition of this reflex pathway would be consistent with inhibition of reflex release of ink by BCPs. Although this has not been directly tested, the L14 ink motor neurons are inhibited by the bag cells for up to $1 \mathrm{hr}$, which may temporarily alter the threshold for sensory activation of this reflex during egg laying (Mayeri et al., 1979). In the present experiments, all animals responded to the training protocol with the release of ink and opaline. It was noted (Goldsmith and Byrne, unpublished observations), however, on at least two occasions, that an animal having received an injection of BCE did not respond to the first train of sensitizing stimuli with release of ink. This would suggest that the BCPs, in addition to modulating the reflex withdrawal of the tail and siphon, were also modulating the ink motor neurons.

Since the BCE contains at least five peptides, it is difficult to determine from these experiments alone which peptide or peptides are responsible for this effect. The administration of ELH to one group of animals in this study, however, can be considered as the first step in this direction. That the ELH treatment did not differ significantly from the control treatment would seem to suggest that the effect of the BCE treatment on the baseline siphon withdrawal is not mediated by the actions of ELH alone. It remains a possibility that more than one peptide may be acting in concert to produce the inhibition of the reflex. Further, the finding that the ABG treatment did not differ significantly from the control treatment indicates that the peptide or peptides contained in the BCE that produced this effect are products unique to the bag cells, rather than common constituents of nervous tissue in general.

An important issue is whether the BCPs are acting directly on the tail-siphon circuitry, or the BCP-induced egg laying activates sensory receptors that in turn activate modulatory circuitry for the reflex. For example, it has been found that sensory input from the reproductive tract produced as the egg string moves through the tract may be important in the inhibition of feeding in Aplysia (Cobbs and Pinsker, 1982). A similar mechanism is unlikely to produce the inhibition of the tail-siphon withdrawal reflex, however. Support for this is provided by the lack of inhibition in the ELH-treated animals. If feedback from the egg string plays any part in producing the inhibition, the ELH-treated animals, all of which did lay eggs, should have 
been affected. In addition, although egg laying began at or after the third trial of the pretraining test period in the BCE group, the inhibition of the reflex was observed to begin with the first trial. Moreover, in semi-intact preparations of the tail in which there is no feedback, preliminary data suggest that BCE may inhibit the tail withdrawal reflex. It should also be noted that the BCPs, in combination and individually (in the case of $\beta$-BCP), attenuate the amplitude of EPSPs in the isolated pleural-pedal ganglion. This indicates that the site of action is more than likely the tail-siphon circuitry. Previously, Mackey and Carew (1983) demonstrated that injection of BCE reversibly suppressed 5-HTtriggered locomotion. This effect also is likely to be due to the effects of the extract on neurons in the pleural-pedal ganglion. The mechanism by which the BCPs may exert their inhibitory effect on the tail-siphon withdrawal circuitry is discussed below.

\section{$B C E$ suppresses long-term sensitization}

In addition to the effect on the baseline tail-siphon withdrawal reflex, these results suggest that one or more of the peptides contained in the BCE are capable of suppressing long-term sensitization of the reflex. Several of the BCPs are thought to be rapidly degraded and therefore have a limited window of biological activity (Sigvardt et al., 1986; Squire et al., 1991; Owens et al., 1992). However, as these experiments suggest, the BCPs have the capacity to produce effects that are rather long lasting. Indeed, in contrast to previous acute studies of the effects of BCPs, these experiments raise the possibility of a new temporal domain ( $>24 \mathrm{hr}$ ) for the effects of these peptides.

As is true for the inhibition of the baseline siphon withdrawal, the role of ELH in suppressing long-term sensitization remains questionable. If ELH plays any role at all, it is most likely expressed at higher concentrations than used in these experiments and/or is limited to a concerted action with one or more of the other BCPs, as ELH by itself does not suppress long-term sensitization.

The suppression of long-term sensitization is surprising in light of the fact that the memory for short-term sensitization is still intact. If both short- and long-term sensitization were suppressed, one could easily offer several explanations. One or more $\mathrm{BCPs}$ might alter the threshold for activation of the facilitatory interneurons in response to the sensitizing stimuli, block the receptor for the facilitatory neurotransmitter, or block the elevation of the second messengers in the sensory neuron necessary for the induction of both the short- and long-term enhancement. An effect on both short- and long-term sensitization does not seem to be the case, however.

An intriguing possibility for the selective effect on long-term sensitization is that the BCPs are acting directly on the processes underlying learning. This is particularly probable considering that there exists a differential effect of the BCE on the shortand long-term forms of sensitization. This leads to the possibility that the BCPs are affecting that part of the mechanism specific to long-term sensitization. Although the mechanisms underlying long-term sensitization have not been fully elucidated, it is known that some of the changes accompanying longterm sensitization are dependent upon new protein synthesis (Castellucci et al., 1989). It is therefore intriguing to speculate that one or more of the BCPs, still active during all or part of the training procedure, interfere with the effect of the neuromodulator, released by sensitizing stimuli, to induce new protein synthesis. Future experiments, using an in vitro analog of longterm sensitization training (Goldsmith and Byrne, 1989; Byrne et al., 1991) to examine the effects of the BCPs, will be necessary to answer this.

An alternative explanation is that both short- and long-term sensitization were suppressed by $\mathrm{BCE}$ and that the enhancement observed at the $5 \mathrm{~min}$ posttraining test is due, at least in part, to the fact that the intensity of the sensitizing stimuli was so strong that the system was saturated. Thus, even though the peptides in the extract may have been active, their effects are not apparent in the behavior.

\section{$\beta-B C P$ attenuates the amplitude of the EPSP}

The electrophysiological experiments examining the effects of $\mathrm{BCE}$ on the sensorimotor synapse revealed that it attenuates the synaptic strength beyond that expected from depression alone. Further, examination of the individual BCPs indicated that only $\beta$-BCP significantly attenuates synaptic strength, and does so independently of presynaptic spike narrowing. Thus, the sensory-to-motor synapse may be one locus for the behavioral inhibition of the reflex by $\mathrm{BCE}$, and $\beta$-BCP may be the peptide contained in the $\mathrm{BCE}$ that is responsible for the inhibition. These studies are the first to indicate that $\beta$-BCP may have an inhibitory role. Previously, the only known role for $\beta$-BCP was autoexcitation of the bag cells (Brown and Mayeri, 1989).

Neither $\alpha$-BCP, $\gamma$-BCP, ELH, nor ARG-VAS significantly affected the EPSP. The fact that $\alpha$-BCP produced no effect was interesting given that the majority of the inhibitory effects on neuronal activity in the abdominal ganglia produced by BCE or by activation of the bag cells have been ascribed to the action of $\alpha$-BCP (Rothman et al., 1983; Rock et al., 1986; Sigvardt et al., 1986). Likewise, the attenuation of sensory-to-motor neuron synapses in the abdominal ganglion produced by ARG-VAS (Goldberg et al., 1987) suggested that it might have similar actions in the pleural-pedal ganglia. Nonetheless, the lack of such an effect by ARG-VAS confirms the specificity of action of $\beta$-BCP on this synapse.

The locus of the actions of $\beta$-BCP could be presynaptic, postsynaptic, or both. While our study of possible postsynaptic mechanisms was by no means exhaustive, we did not find a significant change in the membrane potential of the motor neuron. There was, however, a small decrease in input resistance produced by $\beta$-BCP in the experiments performed in ASW, which became significant at trial 10 . A similar effect was not found in the experiments performed in TEA, however. An explanation for this disparity between the two sets of experiments may be that $\beta$-BCP increases the motor neurons conductance by increasing the permeability to $\mathrm{Na}^{+}$, an effect that may have been diminished in experiment 4 , which was performed in low $\mathrm{Na}^{+}$. Thus, the decrease in input resistance observed in experiment 3 , although only significant at trial 10 , may play a role in the attenuation of synaptic strength produced by $\beta$-BCP. Alternatively, $\beta$-BCP may have as a target some of the currents that are blocked by TEA. This would help to explain why in the presence of TEA we did not see a decrease in input resistance and by extension why the magnitude of attenuation was not as great in the experiments performed in TEA. Interestingly, application of BCE also did not produce a significant change in the input resistance of the motor neuron. A possible explanation for this finding is that the various BCPs contained in the BCE (some of which have not been tested independently in these studies) have opposing effects on the input resistance of the motor neuron, such that the net effect is difficult to detect. Alternatively, the absence of an effect of BCE may be explained 
by differences in the concentrations of the BCPs found in the $\mathrm{BCE}$ and those used in the experiments in which the BCPs were applied individually.

With regard to possible presynaptic mechanisms, the effects on synaptic strength do not appear to be due to changes in duration of the action potential or in the resting membrane potential of the sensory neuron. The lack of an effect on spike duration by $\beta$-BCP is also consistent with the finding that there was no significant difference between the control and $\beta$-BCP experiments in the time to peak of the EPSP. As we are recording only from the soma of the sensory neuron, it remains a possibility that spike narrowing does occur at the terminals of the sensory neuron, where modulation of currents such as $I_{\mathrm{Ca}}$ or $I_{\mathrm{K} . s}$ may be more consequential. However, as there was no change in the time to peak of the EPSP, which, if present, might reflect a change in the duration of the action potential at the terminals of the sensory neuron, we assume that spike narrowing at the terminals may also be negligible. Again, as mentioned above in the discussion of possible postsynaptic mechanisms, there remains the possibility that $\beta$-BCP produces a small amount of narrowing of the action potential and decreases synaptic transmission in part by enhancing $I_{\mathrm{K}, \nu}$. This effect would be abolished in experiments performed in TEA.

Nonetheless, the above results, combined with the fact that there was a significant decrease in slope of the EPSP, support the hypothesis that the attenuation of synaptic strength produced by $\beta-\mathrm{BCP}$ is due, at least in part, to a decrease in the activity of an SDI process (e.g., mobilization of transmitter), rathcr than to a decrcase in spike duration (Hochner et al., 1986; Gingrich et al., 1988; see also Pieroni and Byrne, 1992). Thus, $\beta$-BCP-induced attenuation may reside in a presynaptic locus and be due solely to changes in aspects of the transmitter release mechanism. This is in contrast to the actions of FMRFamide, a neuromodulatory peptide believed to contribute to behavioral inhibition of the siphon-withdrawal reflex (Mackey et al., 1987). FMRFamide decreases both the SDI process (Pieroni and Byrne, 1992) and the duration of the action potential (Abrams et al., 1984). In addition to the possible contribution a decrease in input resistance of the motor neuron may make toward the attenuation of synaptic strength produced by $\beta$-BCP, other postsynaptic factors may also be of importance. For example, an antagonistic role of $\beta$-BCP with the postsynaptic receptors would also be consistent with an attenuated EPSP.

An issue that the present experiments do not address is whether these peptides are acting directly on the pre- and postsynaptic neurons, or indirectly via the activation of inhibitory neurons, the neurotransmitter(s) of which would then effect these changes. However, the experiments performed in low $\mathrm{Na}^{+}$suggest that the modulation by $\beta$-BCP may be a direct effect.

Additionally, it should be pointed out that there is no evidence as yet that the tail-siphon withdrawal reflex or the changes in synaptic strength seen in the isolated nervous system occur after endogenous release of the BCPs (e.g., by stimulation of ELHor BCP-containing neurons). Indeed, before the role of the BCPs, and in particular $\beta$-BCP, can be clearly established, it will be necessary to determine whether injection of $\beta$-BCP produces the same behavioral effects as injection of $B C E$, whether injection of BCE leads to an afterdischarge in the bag cells and thus to the release of additional BCPS, whether the behavioral modifications occur in intact animals during spontaneous egg laying or induction of cgg laying by clectrical stimulation of bag cells, and whether the discharge of the bag cells and/or other $\beta$-BCP- containing neurons in the in vitro preparation leads to changes in the amplitude of the EPSP.

Nonetheless, these experiments, as in previous studies in vertebrate model systems, demonstrate the variety of potential roles peptides may assume in the nervous system. The BCPs have previously been demonstrated to exert effects only on those behaviors that accompany egg laying or that are crucial for egg laying to occur. The present study suggests that these peptides may be important in other roles as well, particularly the inhibition of defensive reflexes. This finding parallels the finding of Advokat (1980) that food stimulation attenuates three defensive behaviors, which include the siphon withdrawal and inking. This is especially meaningful given that fecding and reproductive behaviors appear to be governed by a common arousal system (Ziv et al., 1991). In addition, these experiments suggest that the BCPs have a dramatic effect on a simple form of learning and memory. As we have identified a potential locus of action for at least one of these effects and a peptide that may exert all, or part, of this action, we now have the opportunity to examine in greater detail the mechanisms by which this peptide acts.

\section{References}

Abrams TW, Castellucci VF, Camardo JS, Kandel ER, Lloyd PE (1984) Two endogenous neuropeptides modulate the gill and siphon withdrawal reflex in Aplysia by presynaptic facilitation involving cAMPdependent closure of a serotonin-sensitive potassium channel. Proc Natl Acad Sci USA 81:7956-7960.

Advokat C (1980) Modulation of defensive reflexes in Aplysia californica by appetitive stimulation. Behav Neural Biol 28:253-265.

Arch S, Berry RW (1989) Molecular and cellular regulation of neuropeptide expression: the bag cell model system. Brain Res Rev 14: 181-201.

Arch S, Smock T (1977) Egg-laying behavior in Aplysia californica. Behav Biol 19:45-54.

Baxter DA, Byrne JH (1989) Serotonergic modulation of two potassium currents in the pleural sensory neurons of Aplysia. J Neurophysiol 62:665-679.

Branton WD, Arch S, Smock T, Mayeri E (1978a) Evidence for mediation of a neuronal interaction by a behaviorally active peptide. Proc Natl Acad Sci USA 75:5732-5736.

Branton WD, Mayeri E, Brownell P, Simon S (1978b) Evidence for local hormonal communication between neurones in Aplysia. Nature 274:70-72.

Brown KO, Mayeri E (1989) Positive feedback by autoexcitatory neuropeptides in neuroendocrine bag cells of Aplysia. J Neurosci 9:14431451.

Brown RO, Pulst SM, Mayeri E (1989) Neuroendocrine bag cells of Aplysia are activated by bag cell peptide-containing neurons in the pleural ganglion. J Neurophysiol 61:1142-1152.

Buonomano DV, Byrne JH (1990) Long-term synaptic changes produced by a cellular analog of classical conditioning in Aplysia. Science 249:420-423.

Buonomano DV, Cleary LJ, Byrne JH (1992) Inhibitory neuron produces heterosynaptic inhibition of the sensory-to-motor neuron synapse in Aplysia. Brain Res 577:147-150.

Byrne JH, Shapiro E, Dieringer N, Koester J (1979) Biophysical mechanisms contributing to inking behavior in Aplysia. J Neurophysiol 42:1233-1250.

Byrne JH, Baxter DA, Buonomano DV, Cleary LJ, Eskin A, Goldsmith JR, McClendon E, Nazif F, Noel F, Scholz KP (1991) Neural and molecular bases of nonassociative and associative learning in Aplysia. In: Activity-driven CNS changes in learning and development, Vol 627 (Wolpaw JR, Schmidt JT, Vaughan TM, eds), pp 124-149. New York: New York Academy of Sciences.

Castellucci VF, Blumenfeld H, Goelet P, Kandel ER (1989) Inhibitor of protcin synthesis blocks long-tcrm bchavioral sensitization in the isolated gill-withdrawal reflex of Aplysia. J Neurobiol 20:1-9.

Chiu AY, Strumwasser F (1984) Two neuronal populations in the head ganglia of Aplysia californica with egg-laying hormone-like immunoreactivity. Brain Res 294:83-93. 
Chiu AY, Hunkapiller MW, Heller E, Stuart DK, Hood LE, Strumwasser F (1979) Purification and primary structure of the neuropeptide egg-laying hormone of Aplysia californica. Proc Natl Acad Sci USA 76:6656-6660.

Cleary LJ, Byrne JH (1985) Interneurons contributing to the mediation and modulation of the tail withdrawal reflex in Aplysia. Soc Neurosci Abstr 11:642.

Cleary LJ, Byrne JH (1986) Associative learning of the gill and siphon withdrawal reflex in Aplysia: interneurons mediating the unconditioned response. Soc Neurosci Abstr 12:397.

Cobbs JS, Pinsker HM (1982) Role of bag cells in egg deposition of Aplysia brasiliana. II. Contribution of egg movement to elicited behaviors. J Comp Physiol 147:537-546.

Coggeshall RE (1967) A light and electron microscope study of the abdominal ganglion of Aplysia californica. J Neurophysiol 30:12631287.

Conn PJ, Kaczmarek LK (1989) The bag cell neurons of Aplysia: a model for the study of the molecular mechanisms involved in the control of prolonged animal behaviors. Mol Neurobiol 3:237-273.

Dudek FE, Blankenship JE (1977a) Neuroendocrine cells of Aplysia brasiliana. I. Bag cell action potentials and afterdischarge. J Neurophysiol 40:1301-1311.

Dudek FE, Blankenship JE (1977b) Neuroendocrine cells of Aplysia brasiliana. II. Bag cell prepotentials and potentiation. J Neurophysiol 40:1312-1324.

Dunnett CW (1955) A multiple comparison procedure for comparing several treatments with a control. J Am Stat Assoc 50:1096-1121.

Frazier WT, Kandel ER, Kupfermann I, Waziri R, Coggeshall RE (1967) Morphological and functional properties of identified neurons in the abdominal ganglion of Aplysia californica. J Neurophysiol 30:12881351.

Gingrich KJ, Baxter DA, Byrne JH (1988) Mathematical model of cellular mechanisms contributing to presynaptic facilitation. Brain Res Bull 21:513-520.

Goldberg J, Colmers W, Edstrom J, Lukowiak K (1987) Suppression of sensory to motor synaptic transmission and narrowing of the sensory neurone action potential by arginine vasotocin in Aplysia californica. J Exp Biol 128:47-62.

Goldsmith JR, Byrne JH (1989) Long-term (24 hr) enhancement of the sensory-motor connection mediating tail withdrawal reflex in Aplysia is produced by nerve stimulation, an in vitro analogue of sensitization training. Soc Neurosci Abstr 15:1283.

Goldsmith JR, Byrne JH (1990) Bag-cell peptide(s) inhibits tail-siphon withdrawal reflex and attenuates sensory to motor neuron synapse underlying tail-withdrawal in Aplysia. Soc Neurosci Abstr 16:595.

Goldsmith JR, Byrne JH (1991) Attenuation of synaptic strength produced by $\beta$-bag cell peptide is not dependent on spike narrowing in tail sensory neurons of Aplysia. Soc Neurosci Abstr 17:1591.

Haskins JT, Blankenship JE (1979) Interactions between bilateral clusters of neuroendocrine cells in Aplysia. J Neurophysiol 42:356-367.

Haskins JT, Price CH, Blankenship JE (1981) A light and electron microscopic investigation of the neurosecretory bag cells of Aplysia. J Neurocytol 10:729-747.

Hochner B, Klein M, Schacher S, Kandel ER (1986) Action-potential duration and the modulation of transmitter release from the sensory neurons of Aplysia in presynaptic facilitation and behavioral sensitization. Proc Natl Acad Sci USA 83:8410-8414.

Howell DC (1987) Statistical methods for psychology. Boston: Duxbury.

Jahan-Parwar B, Fredman SM (1976) Cerebral ganglion of Aplysia: cellular organization and origin of nerves. Comp Biochem Physiol [A] 54:347-357.

Jung LJ, Scheller RH (1991) Peptide processing and targeting in the neuronal secretory pathway. Science 251:1330-1335.

Kandel ER (1976) Cellular basis of behavior. San Francisco: Freeman.

Kandel ER (1979) Behavioral biology of Aplysia. San Francisco: Freeman.

Kirk MD, Taussig R, Scheller RH (1988) Egg-laying hormone, serotonin, and cyclic nucleotide modulation of ionic currents in the identified motoneuron B16 of Aplysia. J Neurosci 8:1181-1193.

Kupfermann I (1970) Stimulation of egg laying by extracts of neuroendocrine cells (bag cells) of abdominal ganglion of Aplysia. J Neurophysiol 33:877-881.

Kupfermann I, Carew TJ (1974) Behavior patterns of Aplysia californica in its natural environment. Behav Biol 12:317-337.
Mackey S, Carew TJ (1983) Locomotion in Aplysia: triggering by serotonin and modulation by bag cell extract. J Neurosci 3:14691477.

Mackey SL, Glanzman DL, Small SA, Dyke AM, Kandel ER, Hawkins RD (1987) Tail shock produces inhibition as well as sensitization of the siphon-withdrawal reflex of Aplysia: possible behavioral role for presynaptic inhibition mediated by the peptide Phe-Met-Arg-Phe$\mathrm{NH}_{2}$. Proc Natl Acad Sci USA 84:8730-8734.

Mayeri E, Rothman BS (1985) Neuropeptides and the control of egglaying behavior in Aplysia. In: Model neural networks and behavior (Selverston AI, ed), pp 285-301. New York: Plenum.

Mayeri E, Brownell PH, Branton WD (1979) Multiple, prolonged actions of neuroendocrine "bag" cells on neurons in Aplysia. II. Effects on beating pacemaker and silent neurons. J Neurophysiol 42:11851197.

Mayeri E, Rothman BS, Brownell PH, Branton WD, Padgett L (1985) Nonsynaptic characteristics of neurotransmission mediated by egglaying hormone in the abdominal ganglion of Aplysia. J Neurosci 5:2060-2077.

Mirolli M, Gorman ALF (1968) Abolition of nerve sheath contraction by glutaraldehyde. Comp Biochem Physiol 25:743-746.

Mora S, Diaz-Veliz G (1985) Luteinizing-hormone-releasing hormone modifies retention of passive and active avoidance responses in rats. Psychopharmacology 85:315-318.

Mora S, Afani A, Kusanovic R, Tapia C, Diaz-Veliz G (1991) Behavioral effects of intracerebral administration of luteinizing hormone releasing hormone (LHRH) in rats. Pharmacol Biochem Behav 38: 705-709.

Nasello AG, Bydlowski CR, Felicio LF (1990) The effect of LHRH on rat conditioned avoidance behavior: interaction with brain catecholamines. Pharmacol Biochem Behav 37:639-642.

Owens DF, Menon JG, Rothman BS (1992) Structure-activity relationship of the neurotransmitter alpha-bag cell peptide on Aplysia LUQ neurons: implications regarding its inactivation in the extracellular space. J Neurobiol 23:656-670.

Painter SD, Kalman VK, Nagle GT, Blankenship JE (1989) Localization of immunoreactive alpha-bag-cell peptide in the central nervous system of Aplysia. J Comp Neurol 287:515-530.

Pieroni JP, Byrne JH (1992) Differential effects of serotonin, FMRFamide and small cardioactive peptide on multiple, distributed processes modulating sensorimotor synaptic transmission in Aplysia. J Neurosci 12:2633-2647.

Pinsker HM, Dudek FE (1977) Bag cell control of egg laying in freely behaving Aplysia. Science 197:490-493.

Pinsker HM, Parsons DW (1985) Temperature dependence of egglaying in Aplysia brasiliana and Aplysia californica. J Comp Physiol [B] 156:21-27.

Pulst S-M, Gusman D, Mayeri E (1988) Immunostaining for peptides of the egg-laying hormone/bag cell peptide precursor protein in the head ganglia of Aplysia. Neuroscience 27:363-371.

Rock MK, Shope SB, Blankenship JE, Schlesinger DH (1986) Effects of synthetic bag cell and atrial gland peptides on identified nerve cells in Aplysia. J Neurobiol 17:273-290.

Rothman BS, Mayeri E, Brown RO, Yuan P-M, Shively JE (1983) Primary structure and neuronal effects of $\alpha$-bag cell peptide, a second candidate neurotransmitter encoded by a single gene in bag cell neurons of Aplysia. Proc Natl Acad Sci USA 80:5753-5757.

Roubos EW, van de Ven AMH, ter Maat A (1990) Quantitative ultrastructural tannic acid study of the relationship between electrical activity and peptide secretion by the bag cell neurons of Aplysia californica. Neurosci Lett 111:1-6.

Scholz KP, Byrne JH (1987) Long-term sensitization in Aplysia: biophysical correlates in tail sensory neurons. Science 235:685-687.

Shope SB, McPherson D, Rock MK, Blankenship JE (1991) Functional and morphological evidence for the existence of neurites from abdominal ganglion bag cell neurons in the head-ring ganglia of $A p l y$ sia. J Comp Physiol [A] 168:539-552.

Shyamala M, Nambu JR, Scheller RH (1986) Expression of the egglaying hormone gene family in the head ganglia of Aplysia. Brain Res 371:49-57.

Sigvardt KA, Rothman BS, Brown RO, Mayeri E (1986) The bag cells of Aplysia as a multitransmitter system: identification of alpha bag cell peptide as a second neurotransmitter. J Neurosci 6:803-813.

Sossin WS, Sweet-Cordero A, Scheller RH (1990) Dale's hypothesis revisited: different neuropeptides derived from a common prohor- 
mone are targeted to different processes. Proc Natl Acad Sci USA 87: $4845-4848$.

Squire CR, Talebian M, Menon JG, Dekruyff S, Lee TD, Shively JE, Rothman BS (1991) Leucine aminopeptidase-like activity in Aplysia hemolymph rapidly degrades biologically active $\alpha$-bag cell peptide fragments. J Biol Chem 33:22355-22363.

Strumwasser F (1984) The structure of the commands for a neuropeptide-mediated behavior, egg-laying, in an opisthobranch mollusc. In: Biosynthesis, metabolism and mode of action of invertebrate hormones (Hoffmann J, Porchet M, eds), pp 36-43. Berlin: Springer.

Strumwasser F, Jacklet JW, Alvarez RB (1969) A seasonal rhythm in the neural extract induction of behavioral egg-laying in Aplysia. Comp Biochem Physiol 29:197-206.

Strumwasser F, Schiller DL, Kent SBH (1987) Synthetic neuropeptide egg-laying hormone (ELH) of Aplysia californica induces normal egglaying: structure-activity studies. Soc Neurosci Abstr 13:38.

Stuart DK, Chiu AY, Strumwasser F (1980) Neurosecretion of egglaying hormone and other peptides from electrically active bag cell neurons of Aplysia. J Neurophysiol 43:488-498.
Walsh JP, Byrne JH (1989) Modulation of a steady-state $\mathrm{Ca}^{2+}$-activated $\mathrm{K}^{+}$current in tail sensory neurons of Aplysia: role of serotonin and CAMP. J Neurophysiol 61:32-44.

Walters ET, Byrne JH, Carew TJ, Kandel ER (1983a) Mechanoafferent neurons innervating tail of Aplysia. I. Response properties and synaptic connections. J Neurophysiol 50:1522-1542.

Walters ET, Byrne JH, Carew TI, Kandel ER (1983b) Mechanoafferent neurons innervating tail of Aplysia. II. Modulation by sensitizing stimulation. J Neurophysiol 50:1543-1559.

Xu Y, Cleary LJ, Byrne JH (1991) Identification of pleural neurons that inhibit tail sensory neurons of Aplysia: correlation with FMRFamide immunoreactivity. Soc Neurosci Abstr 17:1590.

Zar JH (1984) Biostatistical analysis. Englewood Cliffs, NJ: PrenticeHall.

Ziv I, Markovich S, Lustig C, Susswein AJ (1991) Effects of food and mates on time budget in Aplysia fasciata: integration of feeding, reproduction, and locomotion. Behav Neural Biol 55:68-85. 